\title{
SALUD, TRABAJO Y NUTRICIÓN. IRLANDA ANTES DE LA HAMBRUNA *
}

CORMAC Ó GRÁDA

University College, Dublin

\section{RESUMEN}

En visperas de la Gran Hambruna (1846-50), los ingresos irlandeses eran bajos según los patrones europeos. Sin embargo, un análisis de las dietas en Irlanda nos sugiere que la pobreza se hallaba mitigada por una ingestión de calorias que sobrepasaba a las de Inglaterra y Francia en los inicios del siglo xIx. Las demandas calóricas extras debidas al trabajo agricola no explican esta desproporción. La impresión de una alimentación saludable queda corroborada por un análisis comparativo entre las estaturas irlandesas y britanicas de finales del siglo xvIII y principios del xIx.

\section{ABSTRACT}

On the eve of the Great Famine (1846-50) Irish incomes were low by west European standards. However, an analysis of Irish diets at the time suggests that poverty was mitigated by a calorific intake that exceeded that of early nineteenth-century England and France. The added physical requirements of farm work in Ireland were not commensurate. The impression of healthy food is corroborated by a comparative analysis of Irish and British heights in the late eighteenth and early nineteenth centuries.

La historia económica de la Irlanda previa a la Gran Hambruna de 184650 va siendo gradualmente mejor conocida, y ello es así en gran medida gracias a las investigaciones de estudiosos foráneos tales como Joel Mokyr y Peter

* Quiero dar las gracias a Margaret Crawford, David Dickson, Joel Mokyr, Leandro Prados de la Escosura, Peter Solar, J. G. Williamson y otros por sus comentarios a un borrador anterior. Algunos de los razonamientos aqui expuestos presentan un mayor detalle en $O$ Grada (1994). Parte de la investigación subyacente fue financiada por NSF Grant 85.0004. 
Solar '. No obstante, este capitulo de la historia aún contiene su parte de paradojas y misterios. Entre ellos se halla el apuntado por el agrónomo irlandés Horatio Townsend en 1810: «no deja de resultar sorprendente el que un pais fértil y bien situado, como es esta isla, y que entró a formar parte del imperio británico en un periodo muy temprano, no pueda dejar aún de mostrar tantos sintomas de pobreza, tosquedad e ignorancia» ${ }^{2}$. Otro misterio seria el por qué la población ( 5 millones en 1800, 8,5 millones en 1845) seguía creciendo tan rápidamente a pesar de la pobreza. Este articulo tratará principalmente de un tercer misterio: el aparente contraste entre la pobreza abyecta de los irlandeses y su situación dietética relativamente elevada.

La pobreza de Irlanda impresionó a famosos visitantes como los ingleses Wakefield (1808-9), Inglis (1834) y Thackeray (1842), franceses como De Beaumont y De Tocqueville (1835) o el alemán German Kohl (1843). Nadie duda de la dificultad de deducir el grado de empobrecimiento a partir de este tipo de impresiones, por vividas que puedan ser. Otras informaciones nos indican que la miseria en Irlanda no era, sin embargo, completamente uniforme. Asi, un visitante alemán a County Galway en 1806-1807, en la parte occidental de Irlanda, citaba que «entre toda esta miseria aun es posible encontrar a personas muy ancianas que fácilmente llegan a alcanzar los cien años». Sería posible citar muchos otros ejemplos de supuesta longevidad. Impresiones de este tipo, en otros contextos, han sido a menudo consideradas como deficientes, pero probablemente la esperanza de vida fue relativamente elevada en Irlanda durante este periodo. En un intento por valorarla de forma indirecta a partir de los datos de distribución por edades de los censos de 1821 y 1841 , se obtiene una cifra de 37.38 años, lo cual es bastante sorprendente, de acuerdo a los estándares de la Europa occidental a comienzos del siglo XIX ${ }^{3}$. Existen también indicios de que la mortalidad infantil era relativamente baja ${ }^{4}$. Tales muestras de un régimen demográfico relativamente «suave» invitan a un examen más minucioso de la salud y la nutrición en la Irlanda previa a la hambruna.

Este articulo consta de tres partes. La Parte 1 aplica el enfoque de cuantificación calórica propuesto recientemente por R. W. Fogel a la Irlanda previa a la hambruna y explica parcialmente la paradoja bajos ingresos-buena dieta. La Parte 2 contiene algunas consideraciones y reservas. La Parte 3 proporciona un debate preliminar a un tema interrelacionado: la intensidad del trabajo. En

1 Ver, por ejemplo, Mokyr (1985); Solar (1987).

2 Townsend (1810), p. 704.

'Woods (1987), 318; Boyle y Ó Gráda (1986), 543-562: Scholield, D. Reher y A. Bideau (eds.). (1991), p. 4.

+ O Grida (1988), pp. 37-38. 
la Parte 4, los datos que aparecen en la Parte 1 sobre la situación nutrimental se relacionan con los resultados de una investigación reciente sobre la estatura de las personas en Irlanda con anterioridad a la Gran Hambruna de la década de 1840 .

\section{UN EJERCICIO DE CUANTIFICACIÓN CALÓRICA}

Nos centraremos fundamentalmente en las tres o cuatro décadas anteriores a la Gran Hambruna, pero unos cuantos comentarios de la conocida obra de Arthur Young Tour in Ireland (1780) nos proporcionan un buen punto de partida. A mediados de la década de 1770, Young halló que los pobres en Irlanda vestian «de forma muy indiferente», y que vivian «en los cuchitriles de aspecto más miserable que uno pueda imaginar». Por otra parte, recibió una impresión favorable por una dieta dominada por las patatas y la leche. El carburante doméstico también era abundante: «el calor en las cabañas era tan sofocante que las piernas de las mujeres llegaban a quedar moteadas por el fuegon. Las valoraciones de Young nos indican una situación que siguió siendo válida hasta 1845 , es decir, los harapientos vestidos y las rudimentarias viviendas de los irlandeses pobres quedaban parcialmente compensados por una dieta completa y abundante y por un combustible doméstico barato.

Las patatas fueron un articulo dominante en la dieta de los pobres con anterioridad a la hambruna. Las estimaciones contemporáneas de Samuel Hayes del consumo anual en la década de 1790 - cuarenta barriles (o, aproximadamente, 30 libras al dia) para una familia de dos adultos y cuatro hijos- «permite apartar algo para echar al perro, a un cerdo y a unas cuantas gallinas»" Las cifras obtenidas a partir de la aritmética política de Austin Bourke ty la depuración de éstas por parte de Mokyr) - para el pobre, de 10 a 12 libras (o 5 kgs.) diarias por varón adulto "- nos permite apreciar mejor la dependencia de la patata con anterioridad a 1845 . En visperas de la hambruna, aproximadamente dos quintas partes de la población dependian de una dieta dominada por las patatas, y el resto consumía enormes cantidades según los estándares actuales. La patata posee defectos bien conocidos - pobre transportabilidad y almacenamiento- pero era un buen alimento. El planteamiento de «explicación vía coste energético» recientemente aplicado por Fogel al consumo de alimentos en Inglaterra y Francia en 1800 nos proporciona una perspectiva útil

\footnotetext{
"Hayes (1797), pp. 8-10.

- Bourke (1968), pp. 72.96; Mokyr (1981), pp. 8-29.
} 
al respecto. La explicación energética conlleva dos etapas. En la primera hay que ajustar la estimación del valor calórico del consumo doméstico de alimentos a la distribución por edades de la población con el fin de calcular el consumo equivalente por varón adulto. En segundo lugar hay que realizar una hipótesis sobre la distribución de ingresos a fin de deducir el consumo probable por cada decil de ingresos.

\section{CUADRO 1}

Simulación de la distribución de la ingestión de calorias de la población irlandesa previa a la Hambruna

\begin{tabular}{|c|c|c|c|c|c|}
\hline & \multirow[b]{2}{*}{ Nivel } & \multicolumn{2}{|c|}{$\begin{array}{l}\text { MODERADAMENTH } \\
\text { KIUALTTARIO }\end{array}$} & \multicolumn{2}{|c|}{ POCO IGLAlmario } \\
\hline & & $\begin{array}{l}\text { Consumo } \\
\text { de Kcal. } \\
\text { diarias }\end{array}$ & $\begin{array}{c}\text { Acumulado } \\
\text { (45) }\end{array}$ & $\begin{array}{c}\text { Consumo } \\
\text { de Kial } \\
\text { diarias }\end{array}$ & $\begin{array}{c}\text { Acumulado } \\
\left(\sigma_{0}\right)\end{array}$ \\
\hline 1. & $\ldots \ldots \ldots \ldots \ldots$ & 5.080 & 100 & 5.783 & 100 \\
\hline 2. & Noveno. & 4.124 & 84 & 4.399 & 82 \\
\hline 3. & Octavo & 3.702 & 71 & 3.818 & 68 \\
\hline 4. & Septimo & 3.399 & 59 & 3.413 & 57 \\
\hline 5 . & Sexto $\ldots \ldots \ldots \ldots \ldots \ldots \ldots$ & 3.157 & 48 & 3.088 & 45 \\
\hline 6. & Quinto $\ldots \ldots \ldots \ldots \ldots \ldots \ldots \ldots \ldots$ & 2.925 & 38 & 2.802 & 35 \\
\hline 7. & Cuarto & 2.709 & 29 & 2.534 & 26 \\
\hline 8. & Tercero ....... & 2.487 & 21 & 2.266 & 18 \\
\hline 9. & $\ldots \ldots \ldots \ldots$ & 2.233 & 13 & 1.967 & 11 \\
\hline 10. & $\ldots \ldots \ldots \ldots \ldots$ & 1.812 & 6 & 1.496 & 5 \\
\hline
\end{tabular}

Nota: El procedimiento seguido es el reseñado en Fogel (1988), p. 45, y en (1990), p. 40.

Peter Solar ${ }^{7}$ nos ofrece una «explicación aproximada de dónde los irlandeses obtenían sus calorias» a comienzos de la década de 1840. Las estimaciones de Solar, que deliberadamente omiten el consumo de productos lácteos y de carne y que están basadas en una discutible y conservadora valoración de la superficie total cultivable de grano, arrojan, sin embargo, unas cifras de con.

F Solar (1989). Solar omitió la carne y los productos lacteos porque los pobres apenas los consumian. Su omision en el presente ejercicio sesga a la baja nuestras estimaciones sobre la in. gestion de alimentos. 
sumo de kilocalorias de 20,5 millones diarias, lo que significa una ingestión media de poco menos de 2.500 kilocalorías al dia. Ahora bien, la ingestión de alimentos necesaria variaba de acuerdo con la edad y el sexo; aplicando un coeficiente corrector de 0,7819 obtenido a partir de la combinación de la distribución de edades del censo de 1841 (haciendo la corrección necesaria para aquellos que "faltaban» en el grupo de edades de (0-4) y la cantidad de alimentos necesaria según la edad y el sexo, aparece una media de 3.168 (es decir, $2.477 / 0,7819)$ kilocalorias para cada unidad de consumo definida como varón adulto ${ }^{8}$. Este nivel de ingestión calórica tan notablemente elevado fue debido en gran medida a la patata. Estos datos se asemejan a las recientes estimaciones de Fogel de 2.700 kilocalorías para Inglaterra en $1785-1795$ y de 2.410 kilocalorias para Francia en 1803-1812. Y para que estas cifras relativas a Irlanda no parezcan increiblemente elevadas, mencionemos que Crawford, por su parte, en sus estimaciones del consumo de calorías con anterioridad a la hambru. na obtenidas a partir de un estudio de las dietas de los trabajadores agricolas de la meridional provincia de Munster en 1839, indica que la ingestión por varón adulto se sitúa en 4.720 kilocalorías ${ }^{9}$. La comparación con el Bangladesh actual amplia el contexto: un estudio reciente del Banco Mundial descubrió que alli la media se situaba por debajo de las 2.000 kilocalorias ${ }^{10}$.

Fogel indica que la cantidad de energia requerida únicamente para el mantenimiento corporal y mental - una dieta de supervivencia - se sitúa entre las 1.700 y las 2.500 kilocalorias para un varón adulto que viva en un clima templado. Este rango refleja la variación por edad y estatura "'. Las implicaciones de aplicar los dos niveles de desigualdad utilizados por Fogel en la distribución de los datos de Solar para la Irlanda previa a la hambruna pueden apreciarse en el Cuadro 1. Es evidente que la hipótesis distributiva afecta más a aquellos situados en la parte superior e inferior. No obstante, incluso el resultado para el caso «poco igualitario» nos sugiere que únicamente una muy pequeña fracción de la población irlandesa pasaba hambre en un año tipo y que, en realidad, podian soportar un importante revés en la cosecha sin que ello implicara una mortalidad excesiva.

\footnotetext{
${ }^{\star}$ Fogel (1988), p. 6. Para un detalle más completo, O Grada (en prensa), cap 4. En su tesis, Solar realiza un cálculo similar, si bien menos detallado, y utiliza un multiplicador de 0.75 . Ver Solar (1987), cap. 9 .

- Parlamentary Papers (1840), «Appendix to the Sixth Annual Report of the Poor Law Commissionersm (245), vol. 17, pp. 675-677; Crawford (1984), pp. 151.161 y 198.211.

${ }^{10}$ Osmani (1990).

"Fogel (1990). pp. 13.14.
} 


\section{CONSIDERACIONES Y RESERVAS}

(i) Las calorias, por si solas, son un representante imperfecto de la calidad alimentaria. No obstante, análisis recientes de la ingestión de vitaminas y proteinas nos indican que los irlandeses tampoco andaban escasos a ese respecto. La revisión que Clarkson y Crawford 12 han efectuado de un estudio sobre los pobres en Irlanda en 1835-1836 nos permite examinar más de cerca lo que sería el tercio inferior de la población: los verdaderamente pobres. No sorprende saber que dicho estudio concluye que la patata era casi universal. La leche también era bastante común, aunque es probable que se tratara de leche ya sin la nata. Los arenques y las gachas de avena jugaban también un papel importante, si bien en menor grado, y la mantequilla, la carne y el pan ya eran muy escasos. Otros posibles articulos - coles, conejos, cebollas, frutas silvestres y vegetales- apenas aparecen en el mencionado estudio. De entre éstos, la col fue probablemente el más importante. Se desconoce la cantidad sembrada con anterioridad a la hambruna, pero de aproximarse a la cultivada a mediados de la década de 1850 entonces, incluso apartando una generosa cantidad para forraje, aún quedaria aproximadamente el equivalente a una libra por semana y varón adulto.

Crawford ha demostrado que la dieta existente con anterioridad a la hambruna no sólo satisfacia las necesidades calóricas de la mayoria de la población mediante las patatas, la harina y las gachas de avena, sino que incluso daba para rechazar el azote de deficiencias vitaminicas tales como el escorbuto, la xeroftalmia y la pelagra, que afectaban a los pobres en otros lugares ${ }^{13}$. La «excepcionalmente elevadas ingestión de proteinas (134,6 g.) propuesta por Crawford fue debida a la patata $(71,6 \mathrm{~g}$.) y al suero de leche $(60 \mathrm{~g}$.). Además, las patatas y el suero de leche aportaban una mezcla correcta de proteínas ${ }^{14}$. La estimación que Crawford hace del consumo de suero de leche es, casi con toda certeza, demasiado elevada, pero incluso con sólo la mitad de una bebida «no únicamente nutritiva y extraordinariamente completa, sino también muy apetitosa y agradable tras un dia dedicado a hacer mantequilla» 15, habria sido más que suficiente. En realidad, las patatas por si solas habrian bastado: la ingestión proteinica recomendada por la FAO/OMS para un varón adulto de 65

12 Clarkson y Crawford (1988), pp. 171-192.

1 Crawford también ha sugerido en correspondencia el alto valor biologico de la proteina de la patata.

14 Crawford (1984), p. 153. Comparese con Burton (1989), p. 373.

15 Hayes (1797), p. 9. 
$\mathrm{Kg}$. es de $37 \mathrm{~g}$., mientras que el gobierno canadiense recomienda $53 \mathrm{~g}$. a sus ciudadanos ${ }^{16}$.

(ii) Una segunda consideración es la relativa a los valores calóricos de las patatas y el grano actuales en relación a las variedades anteriores a la hambru. na. Suponer que existia una paridad podría ser válido para el maiz, pero ¿es plausible para las patatas? Eran varias las variedades de patatas que se cultivaban y comercializaban en la Irlanda previa a la hambruna, incluyendo a la am. pliamente cultivada Lumper. La variedad Lumper fue introducida desde Escocia alrededor de 1810 . Su mala reputación alimenticia queda recogida en afirmaciones de la época tales como ${ }^{17}$ :

Es ciertamente imposible considerar la variedad Lumper como alimento para el hombre. Mézclese la susodicha con cualquier otra clase de patatas, déjese delante de un cerdo y éste no comerá ninguna de aquéllas hasta no haber devorado todas las buenas, incluso aunque su apetito no haya disminuido en absoluto.

Existen muchos más comentarios de este tipo, pero la variedad Lumper resulta doblemente notoria, ya que su propension hacia la phytophthera infestans desempeño un papel clave durante la hambruna. Fue esta debilidad la responsable de su mala reputación en años anteriores ${ }^{1 x}$. En tanto que de aspectos nutrimentales se trate, son dos los puntos a debate. En primer lugar, ¿cuán mala era la calidad de la variedad Lumper con respecto a las otras variedades? En segundo lugar, ¿cuál era su grado de dominancia? Yo creo que las críticas a la variedad Lumper (o a clones de la misma) han sido exageradas en cierta medida. No hay duda de que la variedad Lumper era más acuosa -es decir, contenía menos fécula - que las variedades de primera calidad de su época. ¿En qué medida fue éste un factor diferencial? El precio es un indicador; en visperas de la hambruna, la variedad Lumper costaba aproximadamente un $25 \%$ menos que la variedad Cup. Pero una calidad superior no sólo refleja el contenido de fécula, sino también su sabor ${ }^{19}$. Asi pues, el diferencial representa un limite superior en el intervalo de valores alimenticios.

La solución particular de Crawford a este problema consistió en comparar la pérdida de peso que las patatas actuales sufren al ser cocinadas con las pérdidas indicadas por Hawley en su informe de 1839 , realizado para los comisionados de las Leyes de Pobres -2 onzas de cada 16- Crawford descubrió que las patatas modernas se evaporaban menos, y sus cálculos (y los de Solar) reflejan

16. Health and Welfare Canada (1983), pp. 38.41.

17 Bourke (1965), pp. 55.56.

is Ó Grada (1989), p. 24.

14 Silberberg (1985), pp. 881.900 . 
la diferencia ${ }^{20}$. El problema de la calidad relativa de las variedades de patatas permite posibles estudios futuros. Aunque la variedad Lumper no ha sido cultivada comercialmente desde hace largo tiempo, aún sobrevive un número de especimenes en unas pocas colecciones de «museo». La sección cientifica del Departamento de Agricultura y Pesca de Escocia en Edimburgo posee una rica colección de tales variedades. Durante la estación de 1991, algunos funcionarios del mencionado departamento tuvieron la amabilidad de cultivar cantidades extra de un cierto número de variedades modernas y de museo (incluyendo la variedad Lumperl, y procedieron a medir los contenidos de materia seca y los pesos específicos. Los resultados del experimento fueron los siguientes: $*$

a. Variedades de control

\begin{tabular}{|c|c|c|c|}
\hline Variedad & $\begin{array}{c}\text { Comtentado } \\
\text { en } \\
\text { materia seca }\end{array}$ & $\begin{array}{l}\text { Contenido } \\
\text { en materiat } \\
\operatorname{seca}\left(o_{0}\right)\end{array}$ & $\begin{array}{c}\text { Pero } \\
\text { especifico }\end{array}$ \\
\hline Nadine & Muy bajo & 17,40 & 1,066 \\
\hline Arran Pilot & Bajo & 22,00 & 1,090 \\
\hline D. Standard & Medio & 19,90 & 1.079 \\
\hline Arran Consul & Medio alto & 25,00 & 1,106 \\
\hline Pentland Dell & Medio alto & 24,90 & 1,104 \\
\hline Kerrs Pink & Alto & 26,30 & 1,114 \\
\hline Golden Wonder .... & Muy alto & $>27,00$ & $>1,115$ \\
\hline
\end{tabular}

b. Variedades de museo

\begin{tabular}{|c|c|c|}
\hline Variedad & $\begin{array}{l}\text { Contenido } \\
\text { en materia } \\
\text { seca }(\%)\end{array}$ & $\begin{array}{c}\text { Peso } \\
\text { especílico }\end{array}$ \\
\hline Champion & $>27,00$ & $>1,115$ \\
\hline Fortyfold & $>27,00$ & $>1,115$ \\
\hline Gregor Cups & 25,20 & 1,107 \\
\hline Lewis Black Potato & $>27,00$ & $>1.115$ \\
\hline Lumper ............ & 24,20 & 1,101 \\
\hline Magnum Bonum & 25,50 & 1.108 \\
\hline Myatt's Ashleaf.. & 25,30 & 1.107 \\
\hline 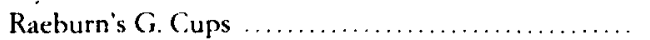 & $>27,00$ & $>1.115$ \\
\hline Skerry Blue .............. & 26,20 & 1,113 \\
\hline Yam $\ldots \ldots \ldots \ldots \ldots \ldots$ & 26,30 & 1.114 \\
\hline
\end{tabular}

20 Parliamentary Papers, «Appendix to the Sixth Annual Report»; Crawford, «Dearth, Diet and Diseasem. Comparense los resultados que aparecen en Bourke (1965), p. 60, y en Ora Smith (1977), p. 607

** Le estoy muy agradecido al señor Douglas MacDonald, del Departamento de Agricultura y Pesca de Edimburgo, y su equipo por cultivar en 1991 cantidades extra de las patatas arriba mencionadas y por llevar a cabo los experimentos aqui descritos. 
Dado que el verano de 1991 fue seco y prematuro, el contenido de materia seca de muchas de las variedades alcanzó el límite superior de la escala hi. drométrica - las lecturas para las variedades de mayor calidad como la Golden Wonder y la Champion sobrepasaron completamente la escala-. No obstante, dado que la variedades de control brotaron más o menos en el orden esperado, las cifras indicadas en la selección de variedades de museo son razonablemente correctas. Según este criterio, la variedad Lumper tendría un rendimiento pobre comparada con las de primera calidad, bien sean modernas o de museo, pero se comporta bastante bien en relación a las variedades modernas de los supermercados.

Los datos que poseemos sobre el segundo punto, la supuesta dominancia de la variedad Lumper, son también muy deficientes. En épocas anteriores, las variedades de patata habian sido muy numerosas ${ }^{21}$. A pesar de la creencia común de que la variedad Lumper habia eliminado a todas las anteriores, las respuestas al cuestionario de la dieta en el Estudio sobre la Pobreza de 1835. 1836 nos indican que aquélla sólo predominaba en algunas regiones, especialmente en la provincia occidental de Connacht. De los veintidós encuestados (de entre varios cientos) que mencionaron la mala calidad de las patatas consumidas, cuatro vivian en el condado de Mayo y tres en el condado de Galway (ambos pertenecientes a Connacht), y la única respuesta de este tipo proveniente del condado de Tipperary (en Munster) se refería a la variedad Lumper de Connacht, mientras que un encuestado de Derry (en el Ulster) se refería a la variedad Cup de Connacht.

(iii) Se suele argumentar que en la Irlanda previa a la Hambruna la escasez de alimentos estacional era endémica. ¿Es posible que afectara a la capacidad para trabajar en julio y agosto, cuando ya se habia agotado la anterior cosecha de patatas y la nueva aún no estaba lista para el consumo o -expresado formalmente- fue esta escasez lo suficientemente importante como para afectar a la salud global de manera sostenida? No poseemos aún respuestas firmes para tales cuestiones ${ }^{22}$. El estudio de los registros que aún se conservan en las parroquias podria proporcionar nuevos datos, pero sólo en el siguiente sentido: en la medida en que una severa falta de alimentos pudiera afectar tanto la capacidad como el deseo de los matrimonios a reproducirse, la escasez en los meses estivales podria haber reducido el número de nacimientos nueve meses después. El nexo de unión entre alimentos y fertilidad resulta controvertido ${ }^{23}$, pero incita de todas formas al estudio de la estacionalidad de los nacimientos.

\footnotetext{
21 Por ejemplo, Dubourdieu (1812), vol. I, p. 205.

22 Comparese Floud et al. (1990), pp. 257-259.

23 Frisch (1978), pp. 22-30; Bongaarts (1980), pp. 564-569.
} 
Mokyr ${ }^{24}$ presenta unos resultados basados en una muestra nacional de regis. tros de la época. El Cuadro 2 resume asimismo las pautas encontradas en una muestra de diecisiete parroquias rurales en el condado de Clare entre 1837. 1840 y $1883-1894$ y en la parroquia urbana de St. Mary's, en Limerick, para un periodo más amplio. Clare se halla incluido por su condición de condado pobre y principalmente rural, Limerick por la perspectiva urbana (si bien sólo la séptima parte de la población de la Irlanda previa a la hambruna vivia en las ciudades). Si el hambre fue lo bastante severa como para afectar a la fertilidad, deberia esperarse un descenso en los bautismos ly, por ende, en los nacimientos) en marzo o abril - pero no existen signos de ello-. La variación estacional que aparece en el Cuadro 2 se asemeja a la registrada en Inglaterra por esa época, tanto en la amplitud como en el tiempo 25.

\section{CUADRO 2}

Estacionalidad de los nacimientos: Clare, Limerick e Inglaterra

\begin{tabular}{lccc}
\hline & Periodo & $\begin{array}{c}\text { Coeficiente } \\
\text { de iariacion }\end{array}$ & $\begin{array}{c}\text { Miximot } \\
\text { mintmo }\end{array}$ \\
\hline Inglaterra & 1750.1799 & 8.4 & 1.32 \\
Clare & $1800-1834$ & 6.3 & 1.26 \\
& 1837.1840 & 10.0 & 1.39 \\
Limerick & 1883.1894 & 7.6 & 1.25 \\
& $1746-1799$ & 5.0 & 1.14 \\
& $1820-1839$ & 5.0 & 1.22 \\
Irlanda & $1861-1896$ & 7.8 & 1.20 \\
Ircland toeste) & 1837.1845 & 8.1 & 1.27 \\
\hline
\end{tabular}

Futxit: Vease el texto. Los calculos tienen en cuenta la variación en el numero de dias de cada mes.

\section{NECESIDADES ENERGÉTICAS Y NUTRICIONN}

¿Es posible que los irlandeses «necesitasen» más calorías porque trabajaban más? Existe, de hecho, una amplia tradición argumental que se extiende por los siglos XVIII y XIX y que hace hincapié en la de las diferencias angloirlan.

24 Mokyr (1985), p. 66.

29 Wrigley y Schofield (1981), pp. 286.287. 
desas en lo que respecta a la calidad e intensidad del trabajo. Sin embargo, lo que en realidad sostiene es que los irlandeses trabajaban menos intensamente ${ }^{26}$. La mayoría de los analistas de la época hacen referencia a un sentido del ocio más desarrollado, si bien un enfoque alternativo pone el acento en una alimentación inadecuada. Arthur Young regresó de Francia convencido de que «el trabajo es en realidad más barato allí donde nominalmente es más costoso. $\mathrm{Si}$ (el trabajador) está bien alimentado y bien vestido... rendirá incomparablemente más que un hombre al que cuya pobreza no le permite sino una alimentación muy escasa» ${ }^{27}$. Ya anteriormente Young habia afirmado que «el trabajo en Irlanda tenia un bajo precio, pero que en modo alguno era baratom. En el mismo sentido, Robert Kane observaba en visperas de la Hambruna que «se observa con frecuencia en los empleos (en Irlanda) un número de manos doble del que seria necesario para llevar a cabo el mismo trabajo, en el mismo tiempo, con trabajadores britanicos. No obstante, Kane creia que el trabajador irlandés se hallaba «tan mal alimentado y tan deprimido mentalmente que trabajar, como un hombre deberia hacerlo, (estaba) más allá de sus posibilidades» 28. Parece ser que Young y Kane intuían que el coste unitario laboral en unidades de eficiencia en Irlanda era superior a lo indicado al comparar ésta con los salarios.

¿Dónde está la verdad en todo esto? La comparación de las tarifas pagadas por periodo trabajado con las tarifas pagadas por trabajo realizado suministra un medio de comprobación, pero sólo bajo circunstancias bastante restrictivas: el producto, su calidad y las técnicas utilizadas deben ser las mismas. Supongamos que descubriéramos que la diferencia entre lo pagado a los cosechadores irlandeses y británicos por dia o por semana fuera mayor a la diferencia entre lo pagado por acre cosechado o segado. En la medida en que la producción por acre y el tipo de utensilios sean los mismos, ello sería consistente (si bien no lo probaria) con una menor intensidad de trabajo en Irlanda. Expresado más formalmente, si las tarifas por trabajo a destajo y por salarios son definidas por $\mathrm{P}$ y W, respectivamente, entonces la gente trabajaría más duro (y requeriria, por tanto, más alimentos) en $i$ que en $j$ si $W_{i} / P_{i}>W_{j} / P_{j}$ o bien si $W_{i} / W_{i}>$ $>\mathrm{P}_{\mathrm{i}} / \mathrm{P}_{\mathrm{i}}$. Descubrir las tarifas por trabajo a destajo apropiadas con las que comparar resulta difícil por las razones ya mencionadas. Probablemente, la fuente más prometedora sea los mercados de trabajo agricolas, pero también disponemos de datos sobre las tarifas por trabajo a destajo fijadas y/o pagadas por diferentes actividades de la construcción - albañileria, techado con pizarra, le-

\footnotetext{
20 Solar y Goossens (1991), pp. 380-381.

27 Young (1929), p. 311.

28 Kane (1845), p. 397. Ver también Mokyr (1991), pp. 177.200.
} 
vantamiento de muros- tanto para Irlanda como para Gran Bretaña desde finales del siglo XVIII hasta comienzos del XIX. Aqui sólo me limitaré a levantar las primeras piedras.

\section{CUADRO 3}

Algunos datos de tarifas por actividad en Irlanda (1810-1811)

\begin{tabular}{|c|c|c|c|c|}
\hline & Leinster & Munster & Ulster & Connacht \\
\hline $\begin{array}{l}\text { Albañiles } \\
\text { (penique por dia) }\end{array}$ & $\begin{array}{c}36,7(4.9) \\
n=23\end{array}$ & $\begin{array}{c}37,9(6.5) \\
n=12\end{array}$ & $\begin{array}{c}34,2(4.5) \\
n=13\end{array}$ & $\begin{array}{c}32,3(3.6) \\
n=7\end{array}$ \\
\hline $\begin{array}{l}\text { Carpinteros } \\
\text { (penique por dia) }\end{array}$ & $\begin{array}{c}37,816.41 \\
n=22\end{array}$ & $\begin{array}{c}38,1(6.7) \\
n=13\end{array}$ & $\begin{array}{c}32,6(3.4) \\
n=7\end{array}$ & $\begin{array}{c}34,3(4.5) \\
n=7\end{array}$ \\
\hline $\begin{array}{l}\text { Albañiles } \\
\text { (penique por vara) }\end{array}$ & $\begin{aligned} 20,4 & (5.0) \\
n & =20\end{aligned}$ & $\begin{array}{c}25,1(8.4) \\
n=10\end{array}$ & $\begin{array}{c}25,0(4.8) \\
n=11\end{array}$ & $\begin{array}{c}19,8(4.7) \\
n=6\end{array}$ \\
\hline $\begin{array}{l}\text { Pizarreros } \\
\text { (penique por dia) }\end{array}$ & $\begin{array}{c}41,0(7.1) \\
n=23\end{array}$ & $\begin{array}{c}40,0(6.6) \\
n=12\end{array}$ & $\begin{array}{c}37.0(4.6) \\
n=10\end{array}$ & $\begin{array}{c}34,3(7.2) \\
\mathbf{n}=7\end{array}$ \\
\hline $\begin{array}{l}\text { Pizarreros } \\
\text { (penique por cuadrado) }\end{array}$ & $\begin{array}{c}101,1(18.5) \\
n=19\end{array}$ & $\begin{array}{c}86,4(18.2) \\
n=10\end{array}$ & $\begin{array}{c}97,2(22.6) \\
n=13\end{array}$ & $\begin{array}{c}104,4(19.0) \\
n=6\end{array}$ \\
\hline $\begin{array}{l}\text { Vallar } \\
\text { (penique por vara) }\end{array}$ & $\begin{array}{c}28,6(12.9) \\
n=14\end{array}$ & $\begin{array}{c}22,9(10.7) \\
n=8\end{array}$ & $\begin{array}{c}23,8(10.6) \\
n=10\end{array}$ & $\begin{array}{c}16,3(2.4) \\
n=4\end{array}$ \\
\hline $\begin{array}{l}\text { Segar hierba } \\
\quad \text { (penique por acre irlandés) }\end{array}$ & $\begin{array}{c}72,8(15.5) \\
n=22\end{array}$ & $\begin{array}{c}70,0(11.5) \\
n=11\end{array}$ & $\begin{array}{c}66,7(17.2) \\
n=12\end{array}$ & $\begin{aligned} 64,1 & (13.5\} \\
n & =7\end{aligned}$ \\
\hline $\begin{array}{l}\text { Segar hierba } \\
\text { (penique por tonclada) }\end{array}$ & 21,4 & 19,3 & 21,5 & 20,3 \\
\hline $\begin{array}{l}\text { Herrar } \\
\quad \text { (penique por caballo) }\end{array}$ & $\begin{array}{c}39,8(4.2) \\
n=21\end{array}$ & $\begin{array}{c}40,4(5.8) \\
n=12\end{array}$ & $\begin{array}{c}39,1(4.2) \\
n=11\end{array}$ & $\begin{array}{c}43,2(5.5) \\
n=6\end{array}$ \\
\hline $\begin{array}{l}\text { Cosechar } \\
\text { (penique al dia) }\end{array}$ & $\begin{array}{c}22.6(5.8) \\
n=23\end{array}$ & $\begin{array}{c}20,0(4.8) \\
n=11\end{array}$ & $\begin{array}{c}19,2(5.5) \\
n=13\end{array}$ & $\begin{array}{c}16,3(3.7) \\
n=6\end{array}$ \\
\hline $\begin{array}{l}\text { Trillar } \\
\text { (penique por dia) }\end{array}$ & $\begin{array}{c}16,1(4.7) \\
n=20\end{array}$ & $\begin{array}{c}20.4(4.5) \\
n=11\end{array}$ & $\begin{array}{c}1+, 2(2.5) \\
n=12\end{array}$ & $\begin{array}{c}13.7(4.5) \\
n=6\end{array}$ \\
\hline $\begin{array}{l}\text { Mano de obra (a. } 1776-8) \\
\text { (penique por dia) }\end{array}$ & $\begin{array}{c}7,4(1.4) \\
n=9\end{array}$ & $\begin{array}{l}6,0(0.4) \\
\pi=12\end{array}$ & $\begin{array}{l}7,3(1.1) \\
n=12\end{array}$ & $\begin{array}{c}5,5(0.4) \\
n=6\end{array}$ \\
\hline
\end{tabular}

FuFitr: Wakefield (1812), vol. II, 208.230; Young (1929), II, 38 -9 (apéndice). Las desviaciones es. tándar, entre parentesis. Al calcular las tarifas por trabajo a destajo de Leinster se han omitido tres casos atípicos. El «cuadrado» del pizarrero constaba de cien pies cuadrados. Se han excluido las cifras de vallado para Stratton (Dundalk) y para Phelps (Limerick). A la hora de estimar el coste de segar hierba, se excluyeron nuevamente las cifras de Phelps, $y$ las dos estimaciones mas bajas de Cork se consideraron referidas a acres reglamentarios. El coste de segar una tonelada de hierba está basado en la producción media conocida para 1847-54. «n" se refiere al número de observaciones. Las tarifas de herrar a los caballos incluyen el coste de la herradura.

La recopilación de datos agricolas por toda Irlanda se inicia con Arthur Young (1780). Más sistemático que Young fue Edward Wakefield (1812), 


\section{CUADRO 4a}

Tarifas por trabajo a destajo y por hora en Irlanda y Renfrewshire, año 1810

\begin{tabular}{|c|c|c|}
\hline Descripción del trabajo & Renfrewshire & Irlanda \\
\hline 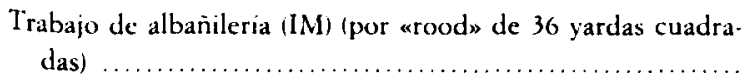 & $9 \mathcal{L}$ & $10 \mathrm{C}(\mathrm{B})$ \\
\hline Enyesar (penique por yarda cuadrada) & 5,5 & de 3,2 a 4,2 (B) \\
\hline Carpinteria (penique por dia) ......... & 42 & 33,9 \\
\hline Albañileria (penique por dia) ...... & 42 & 33.1 \\
\hline Mano de obra (penique por dia) ... & 26 & 11 \\
\hline 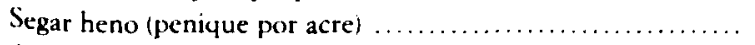 & 43 & 40 \\
\hline 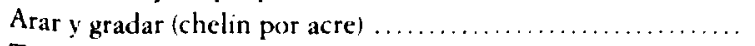 & de 16 a 20 & $18 *$ \\
\hline 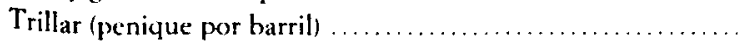 & de 10 a 12 & de 8 a $10 * *$ \\
\hline
\end{tabular}

FUtrtes: J. Wilson (1810), 158-9, 195; Wakefield (1812); Archivos Nacionales, Dublin (Bryan Bolger Papers). Todas las medidas en acres reglamentarios. Los datos marcados con (B) estan basados en las mediciones de Bolger. «IM» significa «incluyendo materiales». Para los albañiles, las varas irlandesas se han convertido en uroods» con la equivalencia indicada en el texto. La moneda irlandesa se ha convertido en moneda britanica al cambio de 1,08 a 1 .

* Trece chelines, seguin dos observaciones, solo para el arado (pp. 221, 223). Gradar habria costado, mas o menos, otros cinco chelines.

** Uno de los informadores (del Ulster) de Wakefield cita un intervalo de $6 \mathrm{p}$. (avena) a $15 \mathrm{p}$. (trigo) por barril, otro habla de $14 \mathrm{p}$. por abollw; otro informador de Dublin de $8 \mathrm{p}$. (cebada y avenal a $11 \mathrm{p}$. (trigo) por barril, otro de $9,5 \mathrm{p}$. por barril. Todos estos precios convertidos a sus equivalentes británicos. El «boll de De Vesci (County Laois) se habla de un precio de 11 p. por barril para este período.

\section{CUADRO $4 b$}

Tarifas por trabajo a destajo y por hora en Irlanda y Kilkenny, 1790-1800

\begin{tabular}{|c|c|c|c|c|}
\hline & \multicolumn{2}{|c|}{ Renfrewshire } & \multicolumn{2}{|c|}{ Kilkenny } \\
\hline & $1792-95$ & 1804 & 1790 & 1800 \\
\hline Segar por acre (p.) & 22 a 30 & - & 23 & 30 \\
\hline Carpintero, albañil (p. por dia) ................ & 22 & 33 & 18 & 24 \\
\hline Sirvientes por año $(£) \ldots \ldots \ldots \ldots \ldots \ldots \ldots \ldots$ & 10 & 15 & 4,6 & 5.5 \\
\hline Mujeres sirvientes por año $(L)$ & 3.75 & 6 & 2,3 & 2,8 \\
\hline Trillar por barril (p.) ............ & 8 & 10 & - & $5 a 6^{*}$ \\
\hline Arar y gradar (ch.) ....... & 14 & & 14,5 & \\
\hline
\end{tabular}

FUENTES: Wilson (1810), 158-9, 195; Tighe (1802), 492-504. Las tarifas y medidas agrarias irlande. sas han sido convertidas a las equivalencias británicas. Un acre de Renfrewshire = = 1.257 acres reglamentarios. * mas dieta. 'se refiere a Hayes (1797), 2. 
quien realizó un estudio basado en la estadistica y otras informaciones recopiladas durante su propio viaje por Irlanda. El Cuadro 3 resume algunos de los datos de Wakefield, recogidos por expertos in situ y que se refieren a las diferen. cias interregionales en Irlanda. Su información sobre los salarios pagados a los cosechadores y a los trilladores por dia confirma la suposición generalizada de que Connacht era la provincia más pobre. No obstante, los datos relativos a la cantidad segada no sirve para confirmar la opinión de que el trabajo en Connacht era «barato» en relación con las otras provincias, y en el caso de los albañiles y pizarreros ocurre, asimismo, que las diferencias interprovinciales son menores para las tarifas a destajo que para las tarifas por dia. En conjunto, a juzgar por las diferencias en algunas tarifas por trabajo a destajo, los datos de Wakefield sirven para apoyar la opinión de que los mercados laborales irlandeses estaban más integrados de lo que se solia pensar. La anomalia más importante de los datos - las bajas tarifas existentes en Connacht para el vallado a destajo- pueden ser debidas a diferencias en calidad. En lo que se refiere a la intensidad del trabajo, los resultados obtenidos son consistentes con la hipótesis de que las gentes en Connacht trabajaban menos intensamente en las diferentes tareas que sus pares de las otras provincias. Las cifras sirven de apoyo a la graciosa descripción que Wakefield hace de los trabajadores de Connacht al decir que malgastan «la mitad del tiempo... en charlar bien con el capataz o entre ellos mismos...». No se puede decir que las mujeres de Connacht fueran muy diferentes: «grupos de jóvenes mujeres empleadas en producir heno o en recoger patatas se abandonan a idénticas actividades, bromeando y riendo con el capataz el dia entero» ${ }^{29}$.

El Cuadro 4 proporciona una perspectiva comparativa. Por el lado irlandés, se basa principalmente en el magistral estudio estadistico de Wakefield y William Tigh, del condado de Kilkenny, y en los registros comerciales de un «medidor» de Dublin, Bryan Bolger. Por el lado británico, la fuente es el estudio del Consejo Agricola de Renfrewshire realizado por John Wilson. Parece bastante sólida la deducción de que el coste laboral (no cualificado) diario era como mucho la mitad tanto en Renfrewshire como en Irlanda. Sin embargo, el margen en las tarifas por actividad era menor, si bien muy variable. En conjunto, las actividades agricolas que se mencionan - trillar, segar, arar - costaban menos por unidad producida en Irlanda, tanto en la década de 1790 como en la de 1800, pero no de forma sustancial. En lo tocante al negocio de la construcción, parece ser que enyesar era más barato en Irlanda, pero no asi la albañileria. En su conjunto, existen pocos indicios de que se cumpla la condición $\mathrm{W}_{\mathrm{IRI}} / \mathrm{W}_{\mathrm{GB}}>\mathrm{P}_{\mathrm{IRL}} / \mathrm{P}_{\mathrm{GB}}$.

${ }^{29}$ Wakefield (1812), vol. II, p. 759. 
Es posible encontrar una perspectiva más amplia acerca de las tarifas agricolas por trabajo a destajo en un estudio sobre Gardeners Chronicle (Crónica de los Jardineros) recientemente rescatado por Clark ${ }^{30}$. El estudio se refiere a 1860, pero en 1860 la fuerza laboral agricola de Gran Bretaña aún superaba el millón, y la mecanización apenas habia rozado actividades de trabajo intensivo tales como cosechar, segar o la recogida de patatas. Mientras que la Gran Hambruna y la emigración habían reducido la fuerza laboral agricola de Irlanda, la mecanización aún habia hecho menos progresos alli. Asi pues, el tipo de datos suministrados por The Gardeners' Chronicle se refiere en gran medida al trabajo en las granjas. Esta fuente proporciona datos sobre las tarifas por actividad y las tarifas por hora. El Cuadro 5 presenta un resumen de los datos. Evi. dentemente, tanto las tarifas semanales como por recolectar eran aún muy bajas en Irlanda, pero desde una perspectiva de trabajo a destajo en el año 1860 , la mayor parte de las ventajas irlandesas habian desaparecido $-y$, en realidad, se habian invertido en relación a Escocia-. No se han realizado ajustes ni por las diferencias en rendimiento (algo más elevada en Gran Bretaña) ni por los suplementos en la dieta (con mayor precio en Inglaterra). Ambos aspectos se movian en direcciones opuestas, aunque yo me atrevería a decir que su efecto combinado podria haber decantado ligeramente la balanza en favor de Irlanda. En su conjunto, si damos crédito a estos datos, en términos de pago por trabajo realizado, la ventaja en favor de los agricultores irlandeses era, como mucho, ligera en el año 1860. Desgraciadamente, el numero de observaciones es dema-

\section{CUADRO 5}

Salarios por recolección y tarifas por trabajo a destajo en Irlanda y Gran Bretaña, 1860

\begin{tabular}{|c|c|c|c|c|}
\hline Zona & Salario semanal & $\begin{array}{l}\text { Salario por } \\
\text { recolección }\end{array}$ & $\begin{array}{l}\text { Coste de segar } \\
1 \text { acre de beno }\end{array}$ & $\begin{array}{l}\text { Coste de cortar } \\
\text { y recoger I acre } \\
\text { de trigo }\end{array}$ \\
\hline Ulster & $6,69(9)$ & $11,31(9)$ & $3.75(7)$ & $9,13(6)$ \\
\hline Leinster. & $6,56(8)$ & $14,44(8)$ & $3,90(6)$ & $11,72(6)$ \\
\hline Munster & $6,56(9)$ & $12,56(9)$ & $3,23(8)$ & $9,91(8)$ \\
\hline Connacht & $5,00(1)$ & $9,50(2)$ & $3,70(1)$ & $7,41(1)$ \\
\hline Irlanda ... & $6,49(28)$ & $12,48(28)$ & $3,60(20)$ & $10,09(21)$ \\
\hline Inglaterra & $10,83(71)$ & $17,91(61)$ & $3,58(70)$ & $11,48(67)$ \\
\hline$\ldots \ldots \ldots$ & $12,40(15)$ & $17.73(12)$ & $3,08(3)$ & $9,44(8)$ \\
\hline
\end{tabular}

Fiente: Gardeners' Chronicle, 28 de abril de 1860.392.3. Las medidas agrarias irlandesas han sido convertidas a las britanicas donde ha sido conveniente.

30 Clark (1989), pp. 679.691. 
siado pequeño como para pronunciarse al respecto de las variaciones regionales en Irlanda.

Volviéndonos brevemente a la industria de la construcción. Humphries (1813) deduce que los honorarios de los constructores variaban escasamente en las diferentes ciudades irlandesas. Por ejemplo, la albañileria con ladrillo costaba entre 22 y 26 p. por vara $(5,29 \mathrm{~m}$.) en Dublin y un poco más en los suburbios. En Cork, los trabajos de albañilería costaban entre $20 \mathrm{p}$. Itercera clase con piedra roja) y $23,5 \mathrm{p}$. (piedra caliza). En Waterford, una vara de mamposteria en grava o en piedra costaba 24 p., y en ladrillo, 18 p. En Belfast, la albañileria en grava costaba 21 p. por vara. En Down oscilaba entre 20 y 22 p. Peter Nicholson (1823) nos ofrece una perspectiva comparativa, situando el coste laboral de una vara de trabajo en piedra en 46 p. $(28$ p. para el albañil y 18 p. para su ayudante) «en el norte y el sur de Irlanda». El trabajo en ladrillo aparece valorado en 36 p. para las afueras de Dublín y en 40 p. para la metrópoli. Una vara contenia 240 ladrillos. En otra parte, Nicholson sitúa el coste de trabajar con 4.500 ladrillos en Inglaterra - un rood inglés- en dos libras (1,5 libras para el albañil y 15 chelines para su ayudante); imenos que las más baja tarifa irlandesa citada por Nicholson!

Tanto las tarifas por trabajo a destajo en la construcción como en la agricultura parecen haber estado más próximas entre sí que las tarifas por hora. En condiciones caeteris paribus, esto sirve de apoyo a la hipotesis de que los irlandeses necesitaban menos calorias, ya que parece ser que trabajaban menos duro en las citadas actividades. Sin embargo, esto no demuestra que los irlandeses trabajasen menos duro a lo largo del año, ya que es posible que trabajasen durante turnos más prolongados en actividades que requieren esfuerzo fisico. En la agricultura previa a la hambruna, el cultivo intensivo con azada le cedió el paso al arado, y la hoz se lo cedió a la guadaña. La siguiente crónica ${ }^{31}$ de una competición de cavar con azada que tuvo lugar cerca de Dublin en 1849 nos sugiere la existencia de un limite superior al área que podía ser cavada en un dia:

La contienda se situó en un lugar colindante con las zonas aradas. El terreno asignado a cada hombre, una vara cuadrada reglamentaria $(24,75$ pies cuadrados), fue cavado en una hora y unos cuantos minutos. Habia 15 participantes, que se pusieron manos a la obra como verdaderos locos. No hace falta decir que se habian despojado de sus chaquetas; también se habian quitado las gorras, y cualquier otra prenda de la que pudieran prescindir. Dos o tres se desma-

"Citado en Bell y Watson (1986), p. 55.

12 Evans (1957), p. 134; Bell y Watson (1986), p. 57. 
yaron cuando terminaron de cavar; seis de ellos tuvieron que ser sangrados durante la competicion; y se sabe de otros que enfermaron gravemente...

Posdata: Posteriormente he sabido que uno de los cavadores de la contienda, un buen trabajador, correcto y capaz, ha muerto a consecuencia de la competicion.

Un acre reglamentario contiene 160 varas. Suponiendo un dia de trabajo de diez horas, arar un acre habria llevado como mínimo dos semanas de trabajo al ritmo de una vara por hora. Estos datos no resultan excesivos: Estyn Evans informaba de un ritmo de veintidós dias por acre, y la tarifa por actividad de un penique por vara citada en 1849 cuadra con esta información 32. Estamos hablando de medias: obviamente, el ritmo de trabajo dependia del tipo de suelo y de la profundidad a la que se cavaba. Un trabajador inglés, armado con un arado y una grada, podía arar un acre en dos o tres dias sin dificultad. Cuando se trataba de segar, las superficies irregulares dejadas por la azada constituian un gran obstáculo para la guadaña. Sólo tras la Hambruna, gracias al aplanamiento de las tierras debido al drenaje subterráneo y al incremento de los salarios agrícolas, pudo la guadaña abrirse paso. La guadaña represento un ahorro en horas de trabajo de aproximadamente la mitad con respecto a la hoz ${ }^{33}$.

Asi pues, ¿cuánta fue la energia ahorrada por todo lo anterior? Dado que la difusión de las diferentes técnicas sólo puede intuirse, y que incluso no hay acuerdo sobre la extensión de la superficie cultivable previa a la hambruna, lo más que podemos hacer es especular. El número de acres para el grano, las patatas y el trebol en la Irlanda de inicios de la década de 1840 era de, aproximadamente, siete millones. La extensión para los mismos cultivos en Inglaterra y Gales era casi del doble ${ }^{3+}$, pero la fuerza de trabajo masculina irlandesa de 1,6 millones de mediados de la década de 1840 excedia a la de Inglaterra y Gales en 1,1 millones. Sin embargo, la yuxtaposición puede conducir a error a causa de las diferentes técnicas utilizadas. Incluso suponiendo que cuatro millones de acres cultivables en Irlanda fueran arados, y un tercio de la cosecha de grano recogido mediante guadaña, las demandas sobre el trabajador irlandés - evaluando ambos a la misma intensidad de trabajo por dia- habrian sido mayores. El cálculo informal realizado en el Cuadro 6 nos aclara por qué. Estima quince dias por acre utilizando la azada, y un ritmo con el arado de medio acre por día. No tiene en cuenta los métodos más intensivos en trabajo a la hora de recoger patatas, o de buscar, transportar $y$ aplicar fertilizantes tales

${ }^{3}$ Bell y Watson (1986), pp. 189-90; Collins (1969), p. 9.

it Holderness (1989), p. 145. 
como algas, arena marina o cal. Por otra parte, el trabajo agricola requeria más esfuerzo físico que el industrial, y en visperas de la Hambruna dos tercios de la fuerza laboral irlandesa era agricola, mientras que en Inglaterra ésta era de un quinto. Estas consideraciones mitigan en cierto modo la suposición obtenida a partir de las tarifas por trabajo a destajo de que los irlandeses «necesitaran» menos calorias. Por otra parte, deben ser enfrentadas a las afirmaciones de Clark de que Inglaterra proporcionaba los mejores trabajadores agricolas de Europa, y a los resultados obtenidos a partir de modernas investigaciones sobre el desempleo estacional en la agricultura irlandesa y británica a comien. zos del siglo XIX ${ }^{35}$, y que indican que el problema era mucho más serio en Irlanda.

\section{CUADRO 6}

Necesidades de mano de obra en el trillado

\begin{tabular}{|c|c|c|}
\hline & Inglaterra y Gales & Irlanda \\
\hline Área cultivada (m.) ..... & 13,8 & 7 \\
\hline Grano $\ldots . . . . . . . . .$. & 7,2 & 3 \\
\hline \multicolumn{3}{|l|}{ Necesidades de mano de obra: } \\
\hline (a) azada/arado (m. dias) $\ldots \ldots \ldots \ldots \ldots \ldots \ldots \ldots$ & $(13,8)(2)$ & $(3)(15)+(4)(2)$ \\
\hline (b) recolección (m. dias) $\ldots \ldots \ldots \ldots \ldots \ldots \ldots \ldots \ldots$ & $(7,2)(1)$ & $(2)(3)+(1)(1)$ \\
\hline Total (m. dias) ......... & 34,8 & 60 \\
\hline Mano de obra masculina (m.) & 1,1 & 1.6 \\
\hline Dias por trabajador $\ldots . . .$. & 31,6 & 37,5 \\
\hline
\end{tabular}

\section{ESTATURA, NUTRICIÓN Y NIVEL DE VIDA}

Esfuerzos recientes por descubrir la tendencia de los niveles de vida irlandeses con anterioridad a la Gran Hambruna, a través de los movimientos en los salarios reales y en el consumo, han producido algunos resultados enigmáticos. En lo tocante a los salarios, los hechos puros de que disponemos no apoyan la tesis del empobrecimiento ni en el periodo de 1780-1781 ni en el de 1815-1845. Lo mismo es válido para el consumo de bienes de importación tales como el té, el azúcar y el tabaco ${ }^{36}$. Y, sin embargo, la evidencia al respecto

"Clark (1989), pp. 679-691: Mokyr (1985), Snell (1985), cap. 1.

36 Mokyr y O Grada (1988), pp. 209.235; Ó Grada, cap. 4. 
es tan impresionantemente unilateral que nos vemos forzados a un examen más amplio. El Índice de Empobrecimiento Subjetivo de Mokyr, basado en un estudio obtenido a partir de la Encuesta sobre los Pobres en Irlanda (Irish Poor Inquiryl de 1835-1836, muestra que la pobreza era generalizada en Irlanda con anterioridad a mediados de la década de 1830 entre aquellos designados como "pobres" por los Comisionados. Tan sólo en un condado de los treinta y tres - Wexford - se indica un inicio de recuperación ${ }^{37}$. La impresión de una pobreza abyecta y generalizada, si no de empobrecimiento, es corroborada en los relatos de observadores de la época bien conocidos como Bicheno (1831), Inglis (1834), Beaumont (1839) y Kohl (1844).

Podria reducir la confusión un análisis de los datos históricos sobre la es. tatura de las personas? La relación entre la estatura, por un lado, y de la situación nutricional e incluso del nivel de vida, por el otro, está hoy ampliamente admitida. Dado que las estaturas medias de los blancos y negros bien alimentados de Europa y Norteamérica de hoy en día son «casi idénticas» ${ }^{38}$, resulta posible dejar a un lado en la presente exposición el papel desempeñado por los factores genéticos. Se apela a menudo a la relación existente entre la estatura y la salud - y, por extensión, el nivel de vida - por parte de los historiadores económicos; frustrados en su búsqueda de una evidencia más directa como podria ser la continuidad de los datos sobre salarios reales o el consumo.

\section{CUADRO 7}

Estimaciones QBE de las estaturas inglesar e irlandesas en la década de 1770

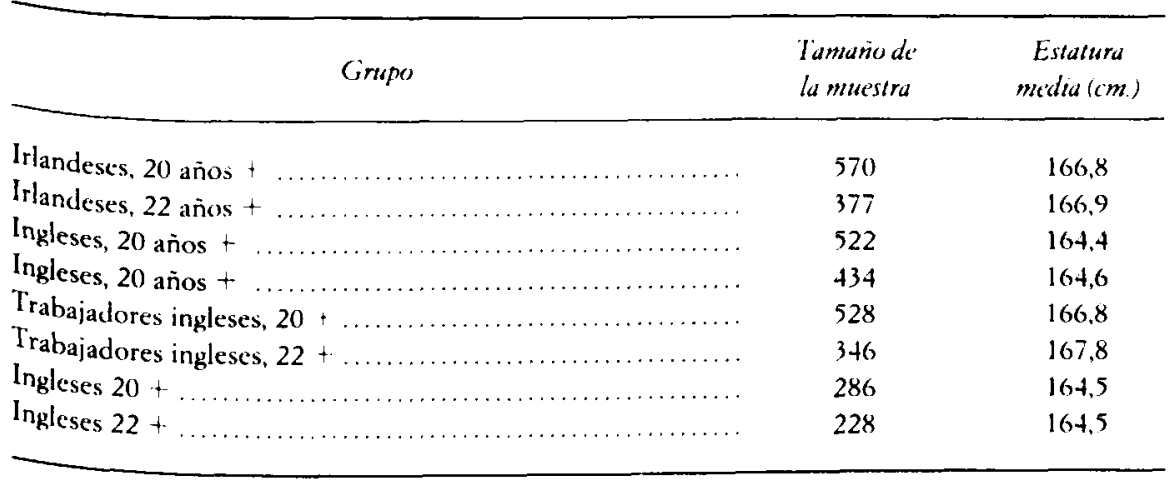

FIENTE: Mokyr y O Gráda (en prensa).

1) Mokyr (1985), p. 12.

sx Fogel et al (1986), p. 251. 
En los países europeos, la más copiosa fuente en datos históricos de estaturas son los registros militares. Los ejércitos han exigido durante mucho tiempo una estatura mínima como método de control de calidad. El análisis de tales datos ha arrojado diversos descubrimientos; a veces sorprendentes, a veces misteriosos. Diversos estudios recientes han incluido a Irlanda, y sus resultados pueden ser resumidos brevemente aqui. En primer lugar, Joe Mokyr y yo hemos utilizado la estatura y otros datos de los varones alistados por Henry Brooke para la Compañía de las Indias Orientales a finales de la década de 1770. A juzgar por sus humildes orígenes, la mayoría de los reclutas habian sido jornaleros en su adolescencia y en su juventud, y habían sido reclutados principalmente, pero en ningún modo exclusivamente, del mismo entorno al que el propio Brooke pertenecía (la parte norte de Leinster, no lejos de Dublín). Se aplicó el algoritmo estándar QBE 39 a las alturas registradas de los hombres de Brooke y a una muestra de reclutas criados en un ambiente similar, en el mismo periodo, en Inglaterra. Dado que el ejército tiende a reclutar a hombres pobres, el QBE también refleja la estatura del pobre. El resultado obtenido aparece en el Cuadro 7. Según los estándares actuales, tanto los irlandeses como los ingleses eran verdaderamente muy bajos. Ello no es sorprendente, pero lo que resulta bastante extraordinario es la deducción de que los irlandeses pobres eran casi una pulgada más altos que los ingleses. Por otra parte, los jornaleros irlandeses no eran más bajos que el resto de los irlandeses, si bien los jornaleros ingleses eran considerablemente más bajos que el resto de sus compatriotas. La comparación se complica por la posible existencia de un sesgo en la selección: dado que los irlandeses eran más pobres, es posible que Brooke y la Compañía de las Indias Orientales fueran capaces de atraer a hombres relativamente mejores. No obstante, la diferencia calculada entre las estaturas irlandesas e inglesas se sigue produciendo tras una comprobación por ocupaciones, y se nos antoja demasiado grande como para ser el simple efecto del mencionado sesgo. Los resultados obtenidos son tentadores, al menos en sus implicaciones en lo relativo a la salud y a la situación nutrimental, e incluso para el bienestar económico en sentido amplio, de finales del siglo XVIII.

En segundo lugar, un análisis de las estaturas de un número mucho mayor de hombres que se alistaron en las filas de la "Compañia John" durante las Guerras Napoleónicas indica nuevamente que los irlandeses fueron reclutados de entre una población de mayor estatura, si bien la diferencia aquí es menor (algo más de un tercio de pulgada). Dentro de Irlanda, la provincia de Munster

\footnotetext{
39 Tal y como se explica en, por ejemplo, Floud, Wachter y Gregory (1990).
} 
y del Leinster rural producían los hombres más altos, y los dublineses eran aproximadamente media pulgada más bajos que la media nacional. Si excluimos Dublín, los hombres irlandeses de las ciudades no eran más bajos que sus compatriotas del campo. Los tejedores eran tipicamente bajos, mientras que los hombres que declaraban haber desempeñado un trabajo «intelectual» antes de alistarse eran casi una pulgada más altos que la media. La comparación indica asimismo una reducción de las estaturas de los irlandeses entre 1770. 1800 , y un incremento de la de los ingleses. Nuevamente estos resultados quedan condicionados por el hecho de que los métodos de reclutamiento, las zonas de captación y las condiciones del mercado laboral diferian notablemente entre los dos períodos y entre las dos islas ${ }^{40}$.

Un análisis más amplio de la estatura de los soldados reclutados entre 1800 y 1860 , cuando el ejército de la Compañía de las Indias Orientales fue licenciado, sugiere que la cantidad y la calidad del consumo de alimentos variaba considerablemente de un periodo a otro. La calidad era pobre en 18001815 y $1857-1858$ y muy alta en la década de 1830 y en la de 1840 . Entre 1841 y 1846, por ejemplo - un período que correspondia aproximadamente a los «Hambrientos Cuarenta»-, la estatura mínima requerida era de sesenta y seis pulgadas, y el 16 por 100 de la ingestión de alimentos de los irlandeses y el 18 por 100 de los británicos que se dedicaban a ocupaciones de «cuello blanco» tales como escribientes, estudiantes, etc., o a trabajos que requerian alfabetismo, como era el caso de los impresores, doblaban la media del periodo 1800-1860. Resulta interesante el hecho de que las variaciones a corto plazo en la calidad de los reclutas, tal y como evidenciaban sus antecedentes ocupacionales, eran muy similares en ambas islas.

Con posterioridad a la década de 1840 , la calidad de los reclutas descendió en relación con la de la mano de obra global. Nuevamente, esto se refleja en los cambios de las ocupaciones anteriores de los reclutas. Más significativo es el hecho de que la proporción de los reclutas de «cuello blanco» virtualmente descendió a la mitad, mientras que la proporción de mano de obra británica pasó de un 35 por 100 del total en la década de 1840 a más del 43 por 100 en la década de 1850. Además, los hombres nacidos en zonas rurales tendían a ser más sanos, y la proporción de reclutas provenientes de zonas urbanas o de pequeñas ciudades también descendió: del 71 al 58 por 100 en Irlan$\mathrm{da}$, y del 51 al 41 por 100 en Gran Bretaña. No es posible justificar este hecho por el proceso de urbanización de ninguna de las dos islas.

La combinación de errores en la anotación de las edades, los puntos de

\footnotetext{
40 Mokyr y Ó Gráda (1989), pp. 83-92; Mokyr y Ó Gráda (en prensa).
} 
corte elevados de las estaturas mínimas y sesgos en la selección de las muestras implica la posibilidad de que los datos no arrojen estimaciones QBE consistentes a través del periodo. El mensaje es el mismo que el de Floud, Wachter y Gregory ${ }^{41}$ : pocos cambios en la estatura media a lo largo del periodo. La estatura implicita - una fracción por encima de las 65 pulgadas- es baja, lo que posiblemente puede ser el reflejo de un descenso relativo del nivel de vida de los soldados (ver más adelante). Pero si, por el contrario, nos centrásemos en la diferencia de estaturas entre los irlandeses y los británicos, el horizonte se amplia. Mokyr y yo estimamos unas series regresivas de las estaturas con respecto a la edad, para modelos que representaban a Irlanda, Escocia, el origen rural y los grupos ocupacionales para diferentes subperiodos. El resultado indica una reducción gradual de la mayor estatura irlandesa a lo largo del tiempo; para el grupo de hombres nacidos en 1840 en Irlanda la diferencia era ya muy pequena. El que los tejedores tendian a ser mas bajos que otros hombres alistados es algo que cuadra con la historiografía. El resultado también confirma el enfasis que la literatura reciente pone en las incomodidades urbanas ${ }^{22}$. Los soldados que previamente habian trabajado en empleos que requerian el alfabetismo eran abiertamente mas altos, lo que indica que aquellos padres que podian permitirse la escolarización de sus hijos también les alimentaban mejor. Los datos de la Compañia de las Indias Orientales implican que en esas décadas la gente de Escocia era más alta que la de Irlanda o Inglaterra. En sentido amplio, nuestros descubrimientos corroboran los de Floud $e t$ al. y Komlos ${ }^{+3}$. Pero nuevamente hay que tener en cuenta el riesgo de sesgos en la selección. Supongamos, hipotéticamente, que los niveles de vida de Inglaterra hubieran permanecido inmutables durante un cierto periodo, mientras que las condiciones en Irlanda hubieran ido claramente a peor. Ello habria inducido a que reclutas de una calidad relativamente mejor se hubieran alistado en Irlanda, incrementando las proporciones de reclutas alfabetos y rurales. $O$ supongamos que las condiciones y la paga hubieran permanecido constantes en el ejército, mientras que los salarios reales de los «paisanos» hubieran crecido. Entonces, los reclutas habrian sido extraidos de una escala socioeconómica cada vez más baja. Yo sospecho que fue algo parecido a esto lo que ocurrió en los efectivos europeos de la Compañia de las Indias Orientales en el periodo en discusión: la paga que los soldados se allevaban a casa» apenas si varió a lo largo de dicho periodo ${ }^{44}$. Un segundo punto atañe al papel

\footnotetext{
4I Floud, Wachter y Gregory (1990).

42 Por ciemplo, Williamson (1989).

"Floud, Wachter y Gregory (1990); Komlos, Imimeo, 1991 ).

it Singh (1976), p. 98; Spiers (1980), p. 53.
} 
desempeñado por la Gran Hambruna. Los voluntarios irlandeses de la década de 1850 fueron extraidos de la población superviviente (posiblemente más sana).

¿En qué medida otras fuentes coinciden con estos resultados? Sokoloff y Villaflor confirman, al menos, la ventaja irlandesa de finales del siglo xvIII. $\mathrm{Si}$ bien descubrieron, en su análisis de una muestra de hombres reclutados por las fuerzas revolucionarias americanas (1775-1783), que los hombres no nacidos en America eran más bajos que los si nacidos, la diferencia entre los colo. nos y los hombres nacidos en Irlanda era tres quintos de pulgada $(01,5 \mathrm{~cm}$.) menos que la diferencia entre americanos e ingleses ${ }^{45}$. Una imagen alternativa de las estaturas de los irlandeses nacidos poco antes de la Hambruna nos la suministran los datos que se han conservado de algunos registros de prisiones. Detallaré aqui los resultados de analizar uno de tales registros: los de la cárcel de Clonmel, del condado de Tipperary, entre 1845 y 1850 . Los hombres y mujeres que figuran en estos registros vivían en la ciudad y las zonas interiores del sur de Tipperary y Waterford; fueron acusados de una panoplia de crimenes que iban desde el conducir una carreta por sitios prohibidos a la violación y el asesinato. Los registros reflejan tanto la «perturbada» situación del campo como - debido a una prostitución endémica- la calificación que Clonmel te. nia de plaza fuerte. La estatura media del varón adulto era bastante elevada -por encima de 66 pulgadas $(167,6 \mathrm{~cm}$.)-. Ello resulta impresionante si se compara con los datos arrojados por la técnica QBE para otros paises a mediados del siglo XIX. Como media, las mujeres eran alrededor de cinco pulgadas (12,7 $\mathrm{cm}$.) más bajas que los hombres. El crecimiento de la pubertad se producia más tarde que hoy en dia, pero antes que en otros datos. Los registros también contienen indicadores del nivel de alfabetización $(« R »$ indicaba sólo capacidad de lectura y “W” capacidad de leer y escribir), y una "W» añadia una impresionante pulgada de más $(2,54 \mathrm{~cm}$.) a la estatura media 46 .

También he examinado una fuente afin: las estaturas que aparecen en el registro de la cárcel de Kilmainham (Dublín) para los convictos deportados. Los resultados (ver Cuadro 8) se basan en más de cuatrocientos hombres deportados por crimenes graves a Australia entre 1841 y 1849 . Aqui la variedad regional es amplia (algo menos de un tercio provenian de las provincias de Leinster y Munster, algo más de un quinto del Ulster, y el resto de Connacht). La información sobre el nivel de alfabetización contenida en los registros está en linea con las precedentes (ver indice), si bien indica que los convictos del

\footnotetext{
45 Sokoloff y Villaflor (1982), p. 462.

th O Grada (1991), pp. 24-33.
} 
Ulster provenian de un ambiente relativamente más pobre que los de otras provincias. El resultado se ajusta bastante bien a los datos sobre Clonmel. Centrándonos únicamente en los hombres de veintitrés años en adelante, la estatura media se situaba por encima de los $168,4 \mathrm{~cm}$. El nivel de alfabetización era importante, pero menos que en Clonmel. También importaba la religión: los 552 católicos de 23 años en adelante tenian una media de $168.7 \mathrm{~cm}$; los 111 protestantes, de 169,9. Nicholas y Steckel, trabajando con datos de convictos provenientes de la parte australiana, confirman la ventaja de estaturas de los irlandeses en el periodo previo a la Hambruna ${ }^{4}$.

CUADRO 8

Los datos de Kilmainham: Estaturas, religión y alfabetización

\begin{tabular}{|c|c|c|c|c|}
\hline & Leinster & Munster & Ulster & Connacht \\
\hline \multicolumn{5}{|l|}{ Estatura $(\mathrm{cm}$.$) :$} \\
\hline Adultos .... & $168,9 \quad(257)$ & $169,5 \quad(25 \pi)$ & $167.3 \quad 11801$ & $167,3 \quad(115)$ \\
\hline \multicolumn{5}{|l|}{ Alfabetización: } \\
\hline Adultos & $1,00(250)$ & $1,00(250)$ & $1,14(168)$ & $0,71(107)$ \\
\hline Católicos $\ldots \ldots \ldots \ldots \ldots$ & $1.05(394)$ & $1.07(304)$ & $0.88(124)$ & $0.68(127)$ \\
\hline Protestantes $\ldots \ldots \ldots \ldots \ldots$ & $1.59(44)$ & $1,53(15)$ & $1,26(93)$ & $1.05(6)$ \\
\hline
\end{tabular}

Nota: La alfabetización se codifica asignando un 0 a los analfabetos, un 1 a los que sabian leer $y$ un 2 a los que sabian leer y escribir.

$\begin{array}{llllcccc}\text { Edad (años) ......... } & 23.24 & 25.29 & 30.34 & 35.39 & 40.44 & 45.49 & 50.54 \\ \text { Estatura (cm.)....... } & 169,2 & 168,6 & 169,2 & 169,3 & 168,3 & 166,0 & 166.4 \\ \text { Observac. ......... } & 125 & 277 & 165 & 91 & 69 & 40 & 26\end{array}$

Las estaturas irlandesas obtenidas a partir de los datos de la prisión y de los convictos eran respetables de acuerdo con los estándares del siglo XIX ${ }^{48}$. Los datos de la Compañia de las Indias Orientales son menos satisfactorios a este respecto, probablemente por alguna de las razones antes comentadas. No obstante, el resultado neto de la investigación auxológica sirve para recordarnos que los tradicionales informes apocalípticos de la pobreza irlandesa previa a la hambruna necesitan ser revisados. La mayor estatura irlandesa también enciende una luz de alarma contra la extremadamente fácil propensión a relacionar la estatura, por una parte, y los niveles de vida y la renta per capita, por la otra.

4: Nicholas y Steckel (en prensa).

48 O Grada (1988), p. 17. 
Existe otra fuente que sigue apoyando la ventaja irlandesa. El estudio realizado por Margo y Goldin de los pesos al nacer en un hospicio de Filadelfia indica que las madres nacidas en Irlanda daban a luz hijos de mayor tamaño que otros grupos inmigrantes. La variación étnica en los pesos al nacer es, probablemente, un indicador de los estándares nutrimentales tan válido para el Viejo Mundo como para el Nuevo ${ }^{49}$.

Nuestros reclutas de la Compañia de las Indias Orientales nos sugieren un conjunto final de observaciones. En la Irlanda previa a la hambruna, la variacion regional de los niveles de vida fue considerable. Mokyr ${ }^{50}$ ha suministrado útiles datos sobre los ingresos por condado, si bien las condiciones variaban considerablemente incluso dentro de los mismos. Tales contrastes regionales son importantes, si bien generalmente ignorados en los libros. Los registros de la Compañia de las Indias Orientales han suministrado una información bastante detallada acerca del origen de los reclutas. Haciendo regresiones de la estatura sobre la edad y modelos ocupacionales como anteriormente se hiciera únicamente para los reclutas irlandeses, y añadiendo modelos regionales, se observa que el Leinster rural produjo los hombres más altos de todo el perio. do. Es de resaltar la estatura relativamente baja de los dublineses y de la gente que habitaba Connacht y la parte occidental de Munster; el Munster oriental también produjo hombres relativamente bajos, mientras que la inicial ventaja en estatura del Ulster oriental sobre el occidental se fue acortando paulatina. mente.

\section{CONCLUSIONES}

Los dos principales bloques de resultados que aqui se han presentado - la ingestión de calorias y la estatura - caminan en la misma dirección. Sugieren que la clave de la relativa gran estatura y longevidad de la Irlanda previa a la hambruna consistió en que, principalmente gracias a la patata, sus gentes estuvieron relativamente bien alimentadas. La alta ingestión de calorias no significa, sin embargo, que los irlandeses pobres estuvieran en una mejor situación que los pobres de otros lugares. Habrian cambiado de buen grado parte de sus calorías por una dieta más variada si bien menos nutritiva - como algunos de ellos hicieron en el periodo posterior a la hambruna-. Los jornaleros del condado de Galway que dijeron en 1835 a los ayudantes de los comisionados que

\footnotetext{
49 Goldin y Margo (1989), pp. 360-379

sil Mokyr (1985), pp. 10-11.
} 
realizaban la Encuesta sobre la Pobreza en Irlanda «no crean a aquellos que les digan que nosotros preferimos patatas Lumper húmedas antes que pan» hablaban en nombre de otros miles. En corte transversal, la consideración que la patata tenia de «bien inferior» resulta asimismo evidente; como ya se ha indicado, el consumo que de ella hacia el pobre equivalia diariamente por varón adulto a 10-12 libras (5 kgs.), mientras que «los trabajadores profesionales y los comerciantes» la consumian al aún considerable ritmo de una libra $(0,5 \mathrm{~kg}$.) diaria 51.

El que los irlandeses deberian haber estado relativamente bien aprovisionados en términos nutrimentales en visperas de uno de los mayores desastres del siglo xIx es una de las ironías de la historia económica de Irlanda y Europa. Las consideraciones anteriormente expuestas podrian erosionar, si bien no invalidar, los descubrimientos globales que indican que la pobreza irlandesa estuvo mitigada por una relativa buena salud. Nuestra aritmética dietética sugiere que los pobres eran capaces de soportar déficit esporadicos en las cosechas; el papel desempeñado por la patata como alimento para hombres y bestias fue el de línea de resistencia añadida. Es posible presentar diversas explicaciones plausibles de «por qué Irlanda murió de hambre» a finales de la década de 1840 - una serie de malas cosechas sin precedente en cuanto a su intensidad y duración, una pobreza y necesidad de tierras que mantuvieron a raya a los ahorros y que dirigió el comercio hacia alimentos baratos, una admi. nistración politica limitada por la ideologia-, pero no será una de ellas una mala salud debida a la falta de alimentos sanos en el periodo que antecedió al desastre.

\section{BIBLIOGRAFÍA}

BELL, J., y M. WATSON (1986): Irish Farming 1750-1900, Edinburgh, 55.

Boncaarts, J. (1980): «Does Malnutrition Affect Fecundity? A Summary of the Evidence», Science, vol. 208, pp. 564-9.

Bourke, P. M. A. (1965): "The Potato, Weather, Blight and the Irish Famine» (tesis doctoral), National University of Ireland, pp. 55-6.

- (1968): "The Use of the Potato in Pre.Famine Ireland», Journal of the Statistical and Social Inquiry Society in Ireland, vol. 12, n. ${ }^{\circ} 6$, pp. 72.96.

BoYl.e, P. P., y C. O GRADA (1986): «Fertility Trends, Excess Mortality, and the Great Irish Faminem, Demography, vol. 23, núm. 4, pp. 543-562.

"1 Bourke (1968), pp. 72.96. 
Burton, W. G. (1989): The Potato 3." ed., Londres.

Clark, G. (1989): «Productivity Growth Without Technical Change in European Agriculture: A Reply to Komlos», Journal Economic History, vol. XLIX, pp. 679-691.

Cl.akkson, L. A., y E. M. CRawFord (1988): «Dietary Directions: A Topographical Survey of Irish Diet, 1836», en R. Mitchison y P. Roebuck (eds.): Economy and Saciety in Scotland and Ireland 1500-1939, Edimburgo, pp. 171-192.

Coli.ins, E. J. T. (1969): Sickle to Combine.

Crawford, E. M. (1984): «Dearth, Diet and Diseases in Ireland, 1850: A Case Study of Nutritional Deficiency", Medical History, vol. 28, pp. 151-161.

- (1989): Famine: The Irish Experience 900-1900, Edimburgo.

Dubourdite, J. (1812): Statistical Account of County Antrim, Dublin.

Evans, E. (1957): Irish Folk Ways, Londres.

Floud, R.; K. Wachter y A. Gregory (1990): Height, Health and History: Nutritional Status in the United Kingdom, 1750-1980, Cambridge.

Fogel., R. W. (1990): «The Conquest of High Mortality and Hunger in Europe and America: Timing and Mechanisms» (NBER Working Paper Series in Historical Factors in Long Run Growth: núm. 16).

- (1988): «Biomedical Approaches to the Estimation and Interpretation of Secular Trends in Labour Productivity, Equity, Morbidity, and Mortality in Western Euro. pe and America, 1780-1980", University of Chicago, Mimeo.

- et al., (1986): «Secular Changes in American and British Stature and Nutrition», en R. I. Rotberg y T. K. Rabb (eds.), Hunger and History: The Impact of Changes in Food Production and Consumption Patterns on Scarcity, Cambridge.

FrISCh, R. E. (1978): «Population, Food Intake and Fertility», Science, vol. 199, pp. 22. 30.

Goldin, C. D., y R. Margo (1989): «The Poor at Birth: Birth-weight and Infant Mortality at Philadelphia's Almshouse Hospital, 1848-73», Explorations in Economic History, vol. 26, núm. 3, pp. 360.379.

HAYES, S. (1797): Essays in Answer to All Queries on the Culture of the Potatoe, Dublin.

Heal.th and Wel.fare Canada (1983): Recommended Nutrient Intakes for Canadians, Ottawa.

Holderness, B. A. (1989): «Prices, Productivity and Output», en G. E. Mingay (ed.), The Agrarian History of England and Wales 1750-1850, vol. VI, Cambridge.

$\mathrm{K}_{\mathrm{ANE}}, \mathrm{R} .(1845)$ : The Industrial Resources of Ireland, Dublín.

Komi.os, J. (1991): "The Secular Trend in the Nutritional Status of the Population of the United Kingdom, 1730-1860m, Economic History Review (en publicación).

Mokyr, J. (1981): «Irish History with the Potato», Irish Economic and Social History, vol. 8, pp. 8-29.

(1985): Why Ireland Starved: A Quantitative and Analytical History of the Irish Economy 1800-1850, 2." ed., Londres.

- (1991): «Dear Labor, Cheap Labor and the Industrial Revolution», en P. Higonnet, D. S. Landes y H. Rosovsky (eds.), Favorites of Fortune: Tecbnology, Growth, and Economic Development Since the Industrial Reublution (Cambridge, Mass.), pp. 177. 200.

Mokyr, J., y C. O Grada, (1988): «Poor and Getting Poorer? Irish Living Standars Be fore the Great Famine», Economic History Review, vol. XLI, pp. 209.235.

- (1989): "The Height of Irishmen and Englishmen in the 1770s", Eighteentb-Century Ireland, vol. 4, pp. 83.92. 
-- (en prensa): «The Heights of the British and Irish c. 1800-1815: Evidence from the Recruits of the East India Company's Armym, en John Komlos (ed.), Anthropometric History.

Nicholas, S., y R. Steckli. (en prensa): «Heights and Health of Workers During the Early Years of British Industrialisation, 1770-1815», Joumal of Economic History.

O GRADA, C. (1988): Ireland Before and After the Famine, Manchester.

- (1989): The Great Irish Famine, Londres.

- (1991): «The Heights of Clonmel Prisoners 1845-9: Some Dietary Implications», Irish Economic and Social History, vol. 17, pp. 24-33.

- (1994): Ireland: A New Economic History, Oxford, Oxford University Press.

OsMaNi, S. O. (1990): «Food Deprivation and Undernutrition in Rural Bangladesh», WIDER Working Paper 82.

Pari.lamentary Paptrs (1840): “Appendix to the Sixth Annual Report of the Poor Law Commissioners» (245), vol. 17.

Schofiet.d, R.; D. Reher y A. Bideau (eds.) (1991): Mortality Decline in Europe, Cam. bridge.

SILBERBF.RG (1985): «Nutrition and the Demand for Tastes», Journal of Political Economy, vol. 93, pp. 881-900.

Singu, M. P. (1976): Indian Army under the East India Company, Nueva Delhi.

Smith, O. (1977): Potatoes: Production, Storing, Processing, $2^{2}$ ed., Westport, Conn.

SNELL, K. M. D. (1985): Annals of the Labouring Poor: Social Change and Agrarian England, 1660-1900, Cambridge.

SokOLofF, K. L., y G. VII.l.AFLoR (1982): «The Early Achievement of Modern Stature in America», Social Science History, vol. 6.

Sol.ar, P. M. (1987): «Growth and Distribution in Irish Agriculture Before the Famine» (tesis doctoral inédita), Stanford University.

- (1989): «The Great Famine Was no Ordinary Subsistence Crisis», en E. M. Crawford, Famine: the Irish Experience, Edimburgo.

Solar, P. M., y M. Goossens, (1991): «Agricultural Productivity in Belgium and Ireland in the Early Nineteenth Century", en B. M. S. Camphell y M. Overton (eds.), Land, Labour and Liveslock: Historical Studies in European Agricultural Productivity, Manchester.

SpIFRs, E. M. (1980): The Army and Society 1815-1914, Londres.

ToW'NSEN, Horatio (1810): Statistical Survey of the County of Cork, Dublin.

WAKEFIEI.D, (1812): Account of Ireland, Statistical and Political Dublin.

Williamson, J. G. (1989): Coping With City Growth During the British Industrial Revolution, Cambridge.

Woons, C. J. (1987): «Johann Friedrich Hering's Description of Connacht, 1806-7», Irish Historical Studies, vol. XXV.

Wrigify, E. A., y R. Schofield, (1981): The Population History of England 1541-1871: A Reconstruction, Londres.

Younc, Arthur (1929): Travels in France, ed. Constantia Maxwell, Cambridge. 